\title{
A Case of Streptococcus bovis Endocarditis Presenting as a Neurosurgical Emergency
}

Santos $\mathrm{MM}^{1 *}$, Belo $\mathrm{D}^{2}$, Cruz $\mathrm{S}^{3}$, Loureiro $\mathrm{J}^{4}$ and Livraghi $\mathrm{S}^{5}$

${ }^{1}$ Neurological Surgery Department, Centro Hospitalar Lisboa Norte, 1649035 Lisboa, Portugal

${ }^{2}$ Neurological Surgery Department, Centro Hospitalar Lisboa Norte, Portugal

${ }^{3}$ Neurology Department, Hospital Fernando Fonseca, Portugal

${ }^{4}$ Hospital Fernando Fonseca, Cardiology Department, Hospital Fernando Fonseca, Portugal

${ }^{5}$ Neurological Surgery Department, Centro Hospitalar Lisboa Norte, Portugal

\section{Introduction}

Rheumatic manifestations have been reported to occur in as many as of $41 \%$ in patients with infective endocarditis (IE) [1]. Back pain is the second most common rheumatic manifestation of IE, although, the occurrence of both infective endocarditis and spondylodiscitis is rare, with an estimated general incidence of $2.5 \%$ [2,3]. Among such cases, Streptococcus bovis is the most frequently isolated etiologic agent due to its specific tropism for vertebra [4]. Streptococcus bovis endocarditis usually presents with an indolent course and tends to occur in older males with underlying colonic pathology [5]. Streptococcus bovis spondylodiscitis commonly affects the lumbar spine, has a slow and insidious onset and is usually managed successfully with intravenous antibiotics [6-8]. To date, there have been only a few reported cases in which an infective endocarditis presented with a cervical epidural abscess. The treatment of spinal epidural abscess usually comprises decompressive laminectomy, debridement and intravenous antibiotics [9]. Exclusive medical is usually reserved for patients with no neurological deficit, poor risk patients with heavy co-morbidities, patients with an extensive epidural abscess (multiple spinal segments affected) and for the ones with complete paralysis lasting for more than three days [10]. Herein we present the case report of a young, healthy male with Streptococcus bovis endocarditis who developed a cervical epidural abscess as the first symptomatic manifestation of his primary disease.

\section{Case Report}

A 42-year old previously healthy male presented to our emergency department reporting a three-week history of progressive worsening neck pain, bilateral upper extremity numbness and night sweats. His past medical history was unremarkable for cardiac disease, liver disease, intravenous drug use, or immunodeficiency. On exam, the patient was awake, oriented and cooperative, with stable vital signs but a tympanic temperature of 38.3 degrees Celsius. An aortic diastolic heart murmur grade III/VI was audible and there was midline tenderness on palpation of the cervical region. There were no motor or sensory deficits or signs of peripheral emboli. A positive Lhermitte sign and a positive right-sided Babinsky sign were recognized. The initial blood workup revealed hemoglobin of $12.4 \mathrm{~g} / \mathrm{dL}$, white cell count of $9.28 \times 109 / \mathrm{L}$, platelets of $159 \times 109 / \mathrm{L}, \mathrm{C}$ reactive protein of $10.2 \mathrm{mg} / \mathrm{dL}$ and a sedimentation rate of $45 \mathrm{~mm}$. Blood cultures were collected. A full spine Magnetic Resonance (MR) with contrast showed a C3-C4 spondylodiscitis and an anterior epidural abscess determining cord compression (Figures 1A and 1B). Multifocal disease was excluded. The patient was taken emergently to the Operating Room (OR) and an anterior approach of the cervical spine, C3-C4 discectomy, drainage of the epidural abscess and intersomatic arthrodesis with autologous iliac bone graft (Cloward technique) were successfully performed. The patient woke-up from anesthesia with no additional focal deficits. A Streptococcus gallolyticus (ex-S. bovis) sensitive to penicillin was isolated on both blood cultures and pus collected intra-operatively and the patient was therefore started on intra-venous penicillin (24M units/

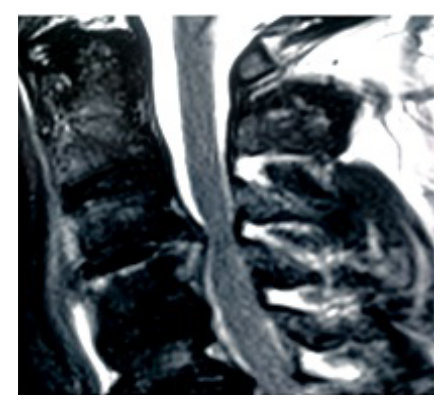

Figure 1A: Preoperative T2 weighted cervical spine MR, sagittal view, showing C3-C4 vertebral endplates erosion with destruction of the intervertebral disc and an epidural abscess compressing the cord.

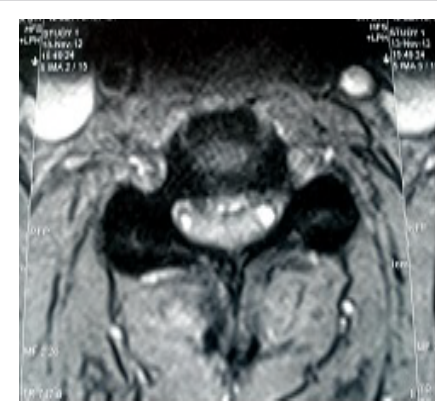

Figure 1B: Preoperative T2 weighted cervical spine MR, axial view, showing a focal anterior epidural abscess compressing the cord.

day) and gentamicin (240mg/day). A trans-thoracic echocardiogram (TTE) and trans-esophageal echocardiogram (TOE) were performed on day 1 post-op and revealed infra-centimetric aortic valve infectious vegetations with moderate to severe aortic regurgitation and partial destruction of one valve leaflet. The aortic disease was considered not surgical. A complete colonoscopy was performed which excluded colonic pathology. The patient was treated with penicillin over 6 weeks and gentamicin over 2 weeks and remained afebrile after the second week of treatment. There was a progressive reduction in the serum inflammatory markers. The surveillance TTE and TOE ruled out intra-

*Corresponding author: Maria M Santos, Neurological Surgery Department, Centro Hospitalar Lisboa Norte, 1649035 Lisboa, Portugal, Tel: 351217972855 ; Fax:351217972855 E-mail: mariamanesantos@gmail.com

Received June 22, 2015; Accepted August 18, 2015; Published August 21, 2015

Citation: Santos MM, Belo D, Cruz S, Loureiro J, Livraghi S (2015) A Case of Streptococcus bovis Endocarditis Presenting as a Neurosurgical Emergency. J Neurol Disord 3: 246. doi:10.4172/2329-6895.1000246

Copyright: (c) 2015 Santos MM, et al. This is an open-access article distributed under the terms of the Creative Commons Attribution License, which permits unrestricted use, distribution, and reproduction in any medium, provided the original author and source are credited. 
Citation: Santos MM, Belo D, Cruz S, Loureiro J, Livraghi S (2015) A Case of Streptococcus bovis Endocarditis Presenting as a Neurosurgical Emergency. J Neurol Disord 3: 246. doi:10.4172/2329-6895.1000246

Page 2 of 3

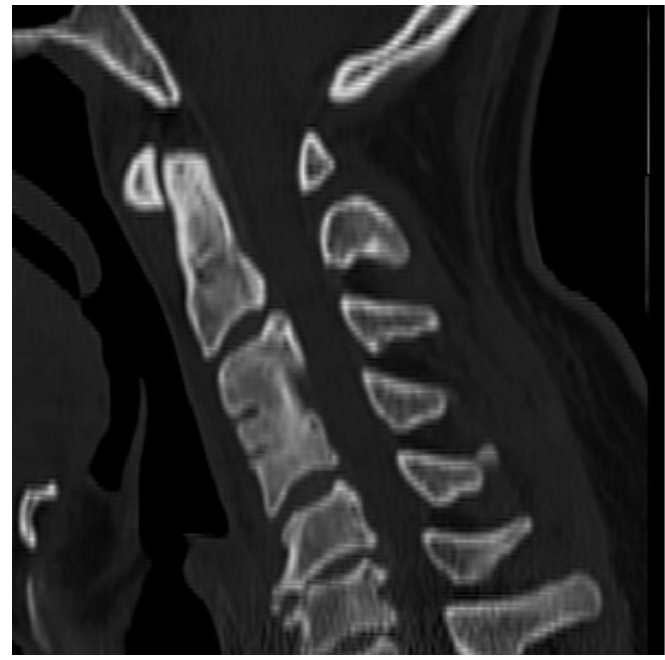

Figure 2: Three months postoperative cervical spine computerized tomography (CT), sagittal view, bone window, showing an adequate C3-C4 fusion.

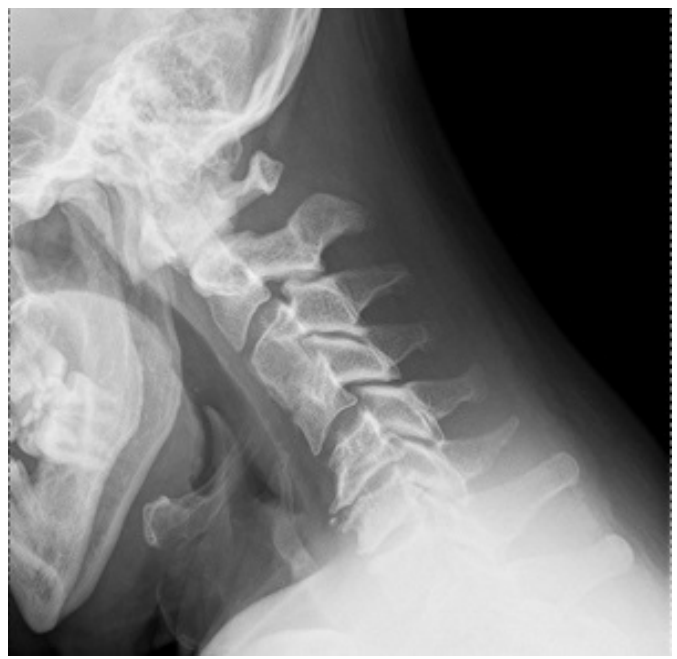

Figure 3: Three months postoperative cervical spine film in flexion, lateral incidence, showing stability of the cervical spine.

cardiac abscess, fistula or pseudoaneurisms. The patient was discharged home 6 weeks after without any sign of congestive heart failure. A one-month interval follow-up TTE showed major aortic regurgitation without associated left ventricular or atrial dilation. Therefore, a regular echocardiographic follow-up was recommended. A cervical spine computerized tomography (CT) (Figure 2) and dynamic cervical spine $\mathrm{x}$-rays (Figure 3 ) were performed 3 months after the surgery and confirmed an adequate intersomatic C3-C4 fusion with no additional osteomyelitis signs. The patient therefore received clearance to return to work.

\section{Discussion}

We report the case of a young male who presented with an epidural cervical abscess that required emergent evacuation in the setting of an unknown IE to Streptococcus bovis. Nevertheless, spondylodiscitis and/or spinal epidural abscess are rare complications of endocarditis (estimated general incidence of 2.5\%) [2,3] and, when diagnosed, are usually associated with Group D Streptococcus endocarditis [4].
Streptococcus bovis is a group D organism found to be an etiologic agent in $5-12 \%$ of infective endocarditis cases $[6,11]$. This agent usually causes a sub-acute type of endocarditis, predominates in elderly males, and is frequently linked to underlying colonic pathology [11]. It also commonly affects the aortic valve [7], although the exact cause for this remains unknown. However, this fact suggests that spondylodiscitis is a consequence of septic embolization from the heart and not the result of bacterial seeding during a bacteremia period. Despite the fact that spondylodiscitis will probably occur later in the disease course, its manifestations are generally the ones that cause the patient to seek medical care [7]. In sum, we report the history of a male who presented with a sub-acute history and was found to have spondylodiscitis in the setting of an underlying infective aortic valve endocarditis to Streptococcus bovis. This case provides an unique example of infective endocarditis caused by S. bovis in a young and healthy male without any proven underlying predisposing factors, who presented to the emergency department with a cervical epidural abscess that required emergent evacuation. The atypical location of the spinal abscess in this setting (the cervical region is the least affected segment of the spine $(7-10 \%)$ in the setting of spondylodiscitis secondary to infective endocarditis [12-15]) and the acute and severe form of presentation make this report unusual. In addition, to the best of our knowledge, there is only one case report of Streptococcus bovis endocarditis presenting as a neurosurgical emergency.

As a limitation of the present report we highlight that the association of these two diseases was already reported as it was the best treatment to offer in this setting.

It is our belief that the awareness of this type of association and its treatment requires further attention and research, as this could potentially lead to higher success in treating the patients in a more efficient way, leading to less morbidity and mortality inherent to these cases.

\section{References}

1. Carey M (1996) Infections of the spine and spinal cord. In: Neurological surgery $\left(4^{\text {th }}\right.$ edn) Philadelphia.

2. Coffey S, Nadarasa K, Pan A, van der Linden A, Chu J, et al. (2012) The increasing incidence of Streptococcus bovis endocarditis and bacteraemia: a case series from 1997 to 2010 . Int J Cardiol 161: 111-113.

3. González-Juanatey C, González-Gay MA, Llorca J, Crespo F, García-Porrúa $C$, et al. (2001) Rheumatic manifestations of infective endocarditis in nonaddicts. A 12-year study. Medicine (Baltimore) 80: 9-19.

4. Grinberg M, Mansur AJ, Ferreira DO, Bellotti G, Pileggi F (1990) [Endocarditis caused by Streptococcus bovis and colorectal neoplasms]. Arq Bras Cardiol 54: 265-269.

5. Kupferwasser I, Darius H, Müller AM, Mohr-Kahaly S, Westermeier T, et al. (1998) Clinical and morphological characteristics in Streptococcus bovis endocarditis: A comparison with other causative microorganisms in 177 cases. Heart 80: 276-280

6. Le Moal G, Roblot F, Paccalin M, Sosner P, Burucoa C, et al. (2002) Clinica and laboratory characteristics of infective endocarditis when associated with spondylodiscitis. Eur J Clin Microbiol Infect Dis 21: 671-675.

7. Mansur AJ, Grinberg M, da Luz PL, Bellotti G (1992) The complications of infective endocarditis. A reappraisal in the 1980s. Arch Intern Med 152: 24282432.

8. Ninet J, Gayet JL, Etienne J, Bonvoisin B, Vignon E, et al. (1984) Bacterial endocarditis presenting as acute vertebral osteomyelitis: 14 cases. Eur Heart J 5 Suppl C: 101-105.

9. Patel AR, Alton TB, Bransford RJ, Lee MJ, Bellabarba CB, et al. (2014) Spinal epidural abscesses: risk factors, medical versus surgical management, a retrospective review of 128 cases. Spine J 14: 326-330.

10. Pergola V, Di Salvo G, Habib G, Avierinos JF, Philip E, et al. (2001) Comparison 
Citation: Santos MM, Belo D, Cruz S, Loureiro J, Livraghi S (2015) A Case of Streptococcus bovis Endocarditis Presenting as a Neurosurgical Emergency. J Neurol Disord 3: 246. doi:10.4172/2329-6895.1000246

Page 3 of 3

of clinical and echocardiographic characteristics of Streptococcus bovis endocarditis with that caused by other pathogens. Am J Cardiol 88: 871-875.

11. Sampath P, Rigamonti D (1999) Spinal epidural abscess: a review of epidemiology, diagnosis, and treatment. J Spinal Disord 12: 89-93.

12. Sharara Al, Abou Hamdan T, Malli A, El-Halabi MM, Hashash JG, et al. (2013) Association of Streptococcus bovis endocarditis and advanced colorectal neoplasia: a case-control study. J Dig Dis 14: 382-387.
13. Speechly-Dick ME, Swanton RH (1994) Osteomyelitis and infective endocarditis. Postgrad Med J 70: 885-890.

14. Thomas P, Allal J, Bontoux D, Rossi F, Poupet JY, et al. (1984) Rheumatological manifestations of infective endocarditis. Ann Rheum Dis 43: 716-720.

15. Tripodi MF, Adinolfi LE, Ragone E, Durante Mangoni E, Fortunato R, et al. (2004) Streptococcus bovis endocarditis and its association with chronic liver disease: an underestimated risk factor. Clin Infect Dis 38: 1394-1400. 